\title{
Smart Control System for Smart City using IoT
}

\author{
Parasa Avinash ${ }^{1}$, B Krishna Vamsi ${ }^{2}$, Thumu Srilakshmi ${ }^{3}$, P V V Kishore ${ }^{4} *$ \\ Department of Electronics and Communication Engineering Koneru Lakshmaiah Education Foundation, Guntur, INDIA
}

\begin{abstract}
As technologies are introducing and improving day by day, there is a tremendous change in the applications like "Smart City". The Internet of Things (IoT) is the best approach to combine various Sensors with Embedded devices to create solutions for the real time problems and this will help us to connect with Internet Society. The term IoT means controlling the things through Internet, in other terminology the objects will "talk" to each other and build some communication to work or to react. There are so many attention-grabbing modules in our society, so in this project we will Implement a model of Smart City with around six elements like Smart Garbage System, Smart Irrigation System, Smart Building, Smart Parking System, Restaurant Menu Ordering System and Manhole Detection and Monitoring System that too in an advanced way. Which means we are going to make some advancement in all these elements like Sending messages by using GSM module with Sensor responses, Sending the information and controlling the components through cloud platform like ADAFRUIT, Accessing webpages through IP Address using Networking domain, Enabling Technologies, Connectivity models and we are going to make all this system automatic. The main objective of this project is without any Human Involvement all the systems or elements has to work to make life easier. The required technologies in this project is Internet of Things (IoT), Embedded Systems and Networking.
\end{abstract}

Keywords-Internet Society; Attention-Grabbing; Networking; Enabling Technologies; Connectivity Models; IP Address; ADAFRUIT; Embedded Systems

\section{INTRODUCTION}

\section{A. Smart Garbage Monitoring System}

In this module we are going to implement a dustbin which will automatically opens the lid when some person reaches towards it, this could be done by using measuring the distance between the person and dustbin. Second aim is to create a webpage using ESP-01 module with reference to the default IP address "192.168.4.1" to store the status of the bin like how much area is filled. And if once the bin is full it will display in the webpage.

\section{B. Smart Parking System}

The main aim of this module aim is to store all the details related to parking place in the could platform called ADAFRUIT. And also to control the entry and exit gates though that platform, it will also maintain the slot timings like then the car is parked and when the car leaves the parking slot.

In this module, first we are going to create a project in ADAFRUIT cloud platform. That project will keep the information about the parking slot like Entry Gate, Exit Gate, Cars Parked, Entry Slot 1, Exit Slot 1, Entry Slot 2, Exit Slot 2, Entry Slot 3, Exit Slot 3. At each and every instance of time that page will update to display the information that was executing in the parking slot. So that we can able to look over the whole process that is going on in the parking slot without any physical appearance. And another thing is once the car appeared at the entrance we can able to open the entry gate automatically by clicking a button on that page created by us, and the same thing was implemented for exit gate also. And another element in this module is special parking, which means if once the car is parked in that slot the owner will get a message like "Your car is parked successfully" and if the car was left from that place the owner will get another message like "Slot is EMPTY".

\section{Smart Building System}

First we are going to implement smart window curtain and smart water pump now let us discuss about the smart water pump this project is aim to design and construct the light sensing blinds to achieve the aforementioned goals. Hardware test results from this project demonstrate the capabilities of smart blind system to measure ambient light inside the room and outside the window, to adjust the angle of each of the blinds on the window, and to change the desired brightness of the room. In the second submodule, based on the sensor values the tap will automatically open when it detect binary digit " 1 " in the values and the tap was closed when it detects the binary digit " 0 ".

\section{Manhole Detection System}

In the existing work of the manhole detection system using IOT they are several drawbacks and many people fall in manhole and die but using this project we can stop that our idea is to create a webpage and sends the information to the person near the Manhole. We are doing this using the GSM module. GSM module sends the message using the webpage. Another important aspect in this module is creating a webpage to store the details related to manhole. This will help to have a complete analysis on the manhole data.

\section{E. Smart Irrigation System using ADAFRUIT IO}

The world is changing as time and so on agriculture. Nowadays, People are integrating electronics in every field and agriculture is not an exception to this. This merging of electronics in agriculture is helping farmers and people who manage gardens. In this article, we will see how to monitor and how to manage gardening and agriculture. We will use (ESP32) controlling module for IoT and we will update the data on the cloud and based on readings we will take the appropriate action. In this project we have used sensors like LDR(Light dependent Resistor), Temperature sensor, Soil Moisture level sensor and we will use the water pump to react on the sensor's data. Apart from this, we can use lots of sensors to monitor.

\footnotetext{
*Corresponding Author
} 


\section{F. Restaurant Menu Ordering System using Webserver}

The main theme of the project is to display the particular item which is ordered by the user and that item should display on the web server with the IP address and hence the web page should consists of the item name, item cost and finally it should print the total cost of item on the webserver by using ESP8266 it can import the data or gather the data through the web server on the transmitter side if the user gives the order of an particular item it should display on the receiver side i.e., on $16 * 2$ display and through web server. At last by using the ESP8266 we can transmit the data through web server and it mainly creates the default IP address on html page such as 192.168.2.1 on that it should display the menu. And for suppose if the user gives the order of a particular item it should display the item name and item cost and total cost of an item through webserver. In this project the user uses the TFT Touch display shield to select the items i.e., when he selected the item it will display the item and item cost on the $16 * 2$ LCD display. Creating a webpage using a hardware module like ESP-01 is a new techniques which will help us to monitor/to see data on webpage, and this webpage will be created with reference to default IP address. The food ordering system is proposed with the use of a handheld device placed on each table which is used to make an order at the restaurant. The system uses a TFT touch plus LCD display module which is placed on each customers table for them to make orders. Order is made by selecting the items displayed on LCD.

\section{RELATED WORK AND ADVANCEMENTS}

\section{A. Drawbacks in Existing Works of Smart Garbage Monitoring System (Fig. 1)}

1) The main drawback is, in this element Human Involvement is needed for some tasks like to clear dust/over flow.

2) Major part of this element depends upon the working of the Wi-Fi module which is operable only in small distances.

3) All the existing works only focus on any one of the perspective like Household or the public places, they don't aim on both the scenarios at a time.

4) For example some of the projects only focusing on intimating the status of bin through mobile app or LCD display in household and another scenario is intimating through message to the municipal officer regarding the status whether full or not in some areas.

5) It is not possible to display the quantity filled in the bin through long distances.

Advancements in this module:

a) The advancement which we are implementing in this element is like sending messages by using GSM module sensor responses.

b) And another important domain used in the project is "NETWORKING". We are going to access this element by using IP address.

c) Which means that we are going to create a webpage and assigning some setup with IP address so that we can able to control/access all these elements at anytime and from anywhere by storing them in a database.

d) The creating of webpage is done by using hardware element like ESP-01, which is modern technique to create a webpage with reference to IP address.

\section{B. Drawbacks in Existing Works of Smart Parking System} (Fig. 2)

1) In the existing works there is no mechanism like sending the SMS to mobile once the car is parked and again the car is moved from the parking place.

2) In existing projects, no one use the specific application to store the information related to parking like ADAFRUIT, Webpages, etc.

3) The time slot is not mentioned in existing works like, when the car is placed and when it is moved from the parking.

Advancements in this module:

a) When the car is placed in the parking place, then one SMS is sent to our mobile like car is placed at position 4. So that no need to go and check where the car is placed.

$b$ ) When the car left from the parking place also we will get a message to our mobile, this will provide a security to our car.

c) In this project I am using an software/application called ADAFRUIT, in that I have created a project mentioning like Number of cars parked, Entry gate(open/close), Exit gate(Open/close), Slot1, Slot2 and Slot3. They will mention all the details of the parking place.

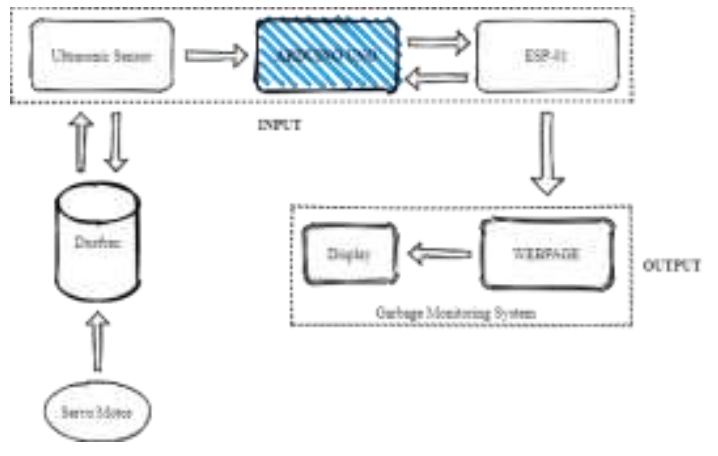

Fig. 1. Block Diagram for Smart Garbage Monitoring System.

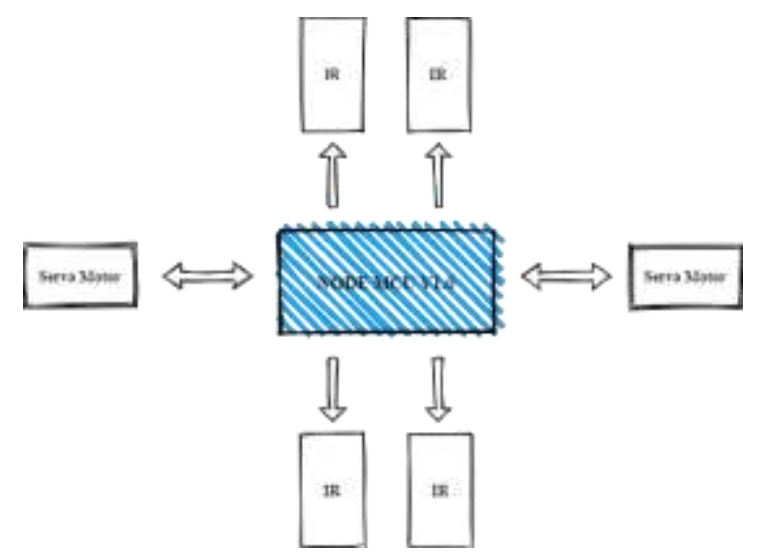

Fig. 2. Block Diagram for Smart Parking System. 


\section{Drawbacks in Existing Works of Smart Building System} (Fig. 3)

1) The disadvantages of a new technology are just as important as the advantages, if not more important. People who are not computer-savvy would not want to live in a smart home since it is completely computer run. People who are not computer-savvy would not want to live in a smart home since it's completely computer run. If someone were to hack a home's system they would have access to controlling the home, like unblocking doors, monitoring the cameras off so they would invalid the home.

2) In existing works I observed that the watering of plants through sprinklers, this mechanism is not implemented for handwash which will reduce the human effort.

Advancements in this module:

a) This project is solving the problem of wasted energy within buildings and homes, because currently the lights turned on inside building do non-utilized natural, ambient light from the sun. Rather than having unnecessary light from a light source, the automated light sensing smart blinds can sense the amount of light outside the window and in the room, and then adjust the angle of the blinds to save energy by utilizing the available outdoor light. This way, the light source will not be running at maximum power output while there is excess light coming through the window.

b) Coming to the tap mechanism, here the human involvement is not needed to open/close the tap. In previous works I observed that watering the plants using sprinklers, based on that mechanism I design this module of automatic open/close the tap.

\section{Drawbacks in Existing Works of Manhole Detection}

System (Fig. 4)

1) Manholes leading to underground supply systems are essential for their maintenance, for example, it concerns telecommunication networks, water supply networks, gas supply networks and electricity networks, and so on. Although it is very crucial to a city's operations, the manhole can be one of the least protected and most vulnerable assets.

2) In previous works, the message sending mechanism is not included which is the main drawback. Now a days mobile is mandatory to every person so, by intimating through an SMS is needed.

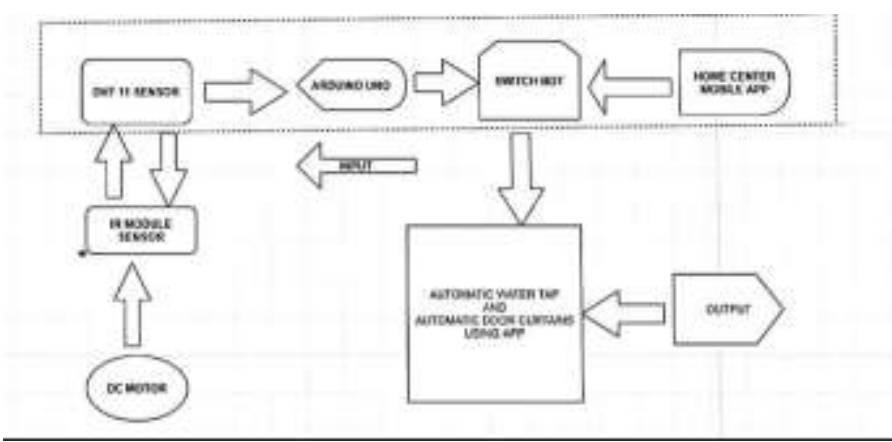

Fig. 3. Block Diagram for Smart Building System.

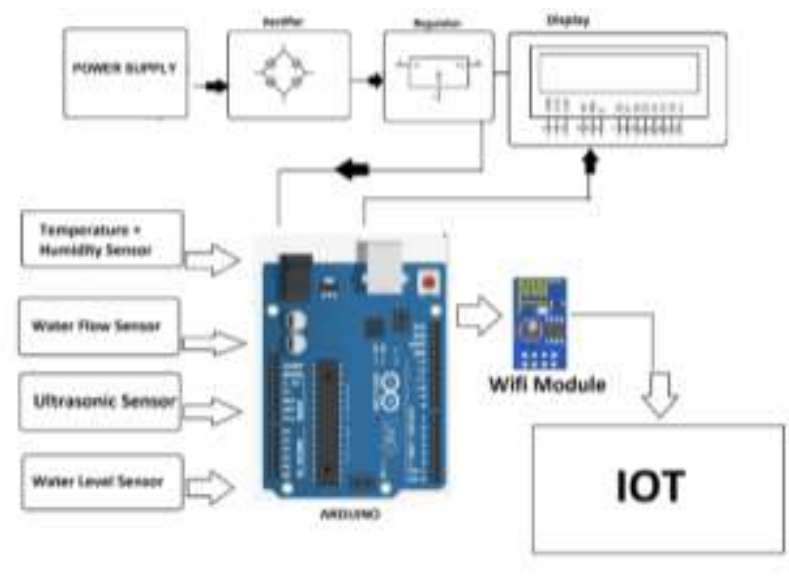

Fig. 4. Block Diagram for Manhole Detection System.

Advancements in this module:

a) The advancement which we are implementing in this element is like sending messages by using GSM module sensor responses.

b) We control and detect man hole by using GSM module sensor. GSM module sensor detect the person near the manhole and sends information to him.

c) We create a webpage to store the information of the person.so when the person comes near the man hole GSM module takes the information and message to him/her by using a webpage. We took up this project to control the falling of people in man hole.

\section{E. Drawbacks in existing works of Smart Irrigation System Using ADAFRUIT (Fig. 5)}

1) The main drawback of this project is without any human involvement all systems has to work make life easier to farmers.

2) Actually the existing work in smart irrigation system is with the human involvement we can control the plants when it is wet or dry state conditions.

3) The another type of existing work in smart irrigation system is using BLYNK app in this with only human involvement it can control the plants whether the plant is in dry or wet condition state.

4) The brilliant farming necessities accessibility of web ceaselessly. Provincial piece of the greater part of the nonindustrial nations don't satisfy this prerequisite. Also web association is much slower.

Advancements in this module:

a) In this module we will see the monitoring and how to manage gardening of agriculture. And in this module we will use the ESP32 module for controlling the garden.

b) In this part we will update the data on the cloud and based on the readings we will take the accurate readings from it.

c) In this project we used LDR, temperature sensor, soil moisture sensor and submersible water pump to react on sensor data. 
d) If the soil moisture level is very low then it will turn ON the Water Pump. We are monitoring the motor status as well for the feedback to confirm the motor status.

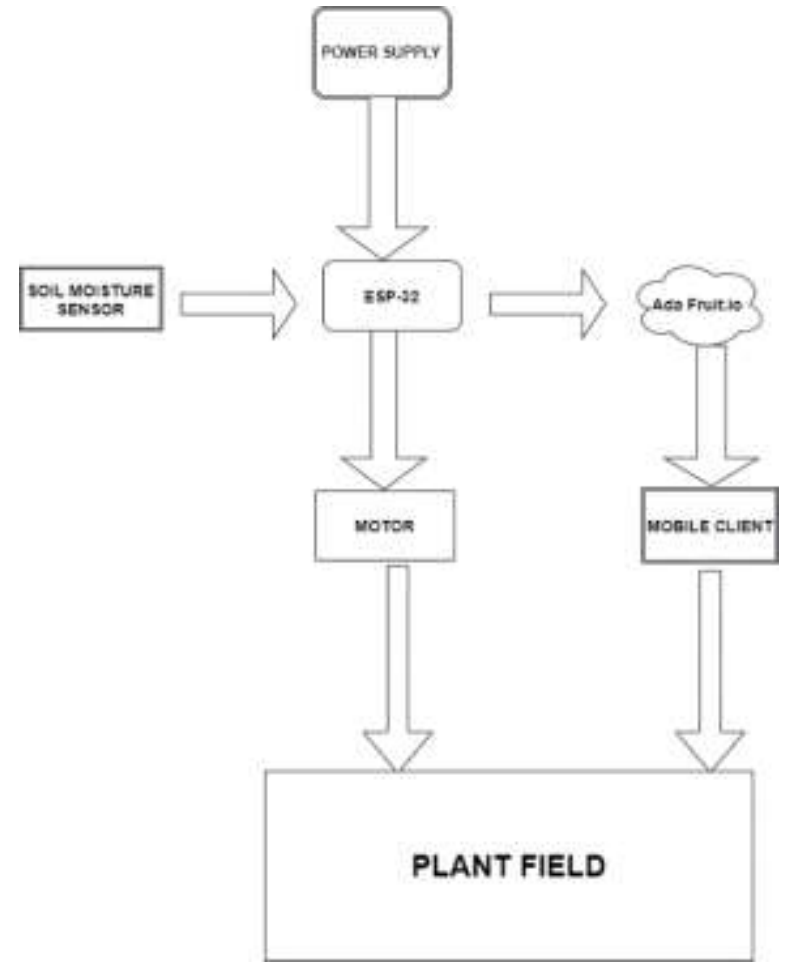

Fig. 5. Block Diagram for Smart Irrigation System.

\section{F. Drawbacks in Existing Works of Restaurant Menu Ordering System (Fig. 6)}

1) In existing Work the user uses the TFT Touch display shield to select the items i.e. when he selected the item it will display the item and item cost on the $16 * 2$ LCD display.

2) The second aim is to create a web page using Esp8266 module with that reference to the default Ip address "192.168.2.1" is used to store the status of the items and cost of the items and total cost of an particular item once if we select a particular item it should display the total cost of the food item and name of the food item through particular web page.

Advancements in this module:

a) Firstly when the user was selected particular item the system should display the selected item name, cost of the item, and at last it should display the total cost of an selected items through the IP address (web server).

b) In this project I am using ESP8266 to import the data or gather the data through the webserver hence with ESP8266 module with that module reference it creates the default Ip address "192.168.2.1" which is used to store the "name of the item", "cost of item", and total cost of all items which we have selected it should display on web page.

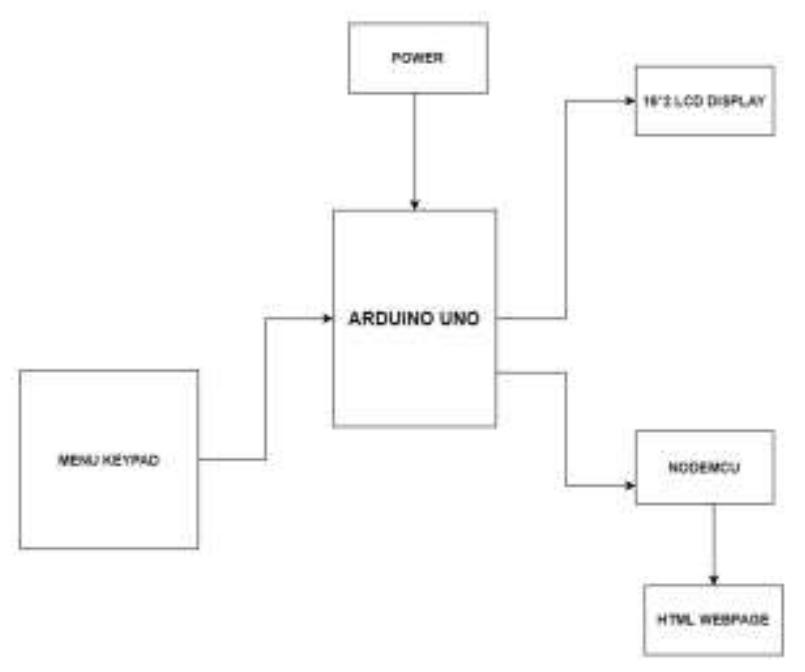

Fig. 6. Block Diagram for Restaurant Menu Ordering System.

\section{RESULTS AND DISCUSSIONS}

\section{A. Smart Garbage Monitoring System}

The first output for this module is lid opening by measuring the distance of the object which is placed infront of it, after opening the lid it will take some delay and automatically closed. This delay time will help us to through the dust in the bin. Secondly, we have to connect to the WIFI module which will appear in out device so that it will create a webpage by using default IP address in the device which was connected to WIFI module. In that webpage we can able to monitor the level of the dustbin and once it was full it will display a message like "Dustbin is full" (see Fig. 7 to 9).

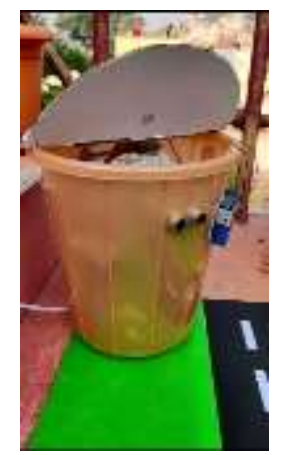

Fig. 7. Opening of Lid.

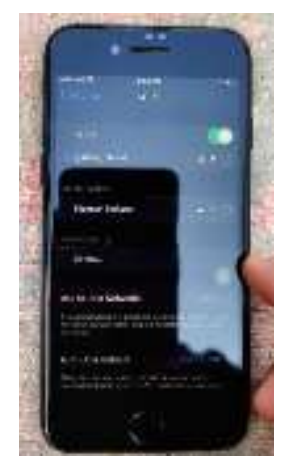

Fig. 8. Connecting to WIFI. 


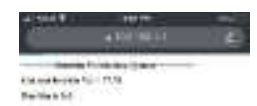

Fig. 9. Webpage Display for Smart Garbage Monitoring System.

\section{B. Smart Parking System}

The first output for this module is to open the entry and exit gates remotely by using the adafruit platform this will help to validate the customer whether he paid the parking fee or not. Secondly, the entry and exit gates has to open automatically when the car is placed infront of the gates. Third and most important output is to display the slot timing of the cars which was placed in parking slots. The number of cars count which enters/leaves the parking place will be updated in the cloud service platform called ADAFRUIT. Another interesting submodule is special parking, when the car was parked in this slot the owner will get a message to their mobile like "Your car is parked successfully !!" and once the car was removed from that slot they will get another message like "Slot is empty !!" this will provide more safety to the car. And based on all these measurements that ADAFRUIT platform will form a graph so that we can have more understanding about each and every slot (see Fig. 10 to 13).

\section{Smart Building System}

The first output of the module is automatic open/close of a curtain. When we clap the window curtain will open and when we clap for another time windows will close (see Fig. 14). And second one is smart water pump when we place hand under the tap, it will automatically on and once we remove the hand under the tap, it will off automatically (Fig. 15). In automatic curtain we use a webpage to record the time how much time did the curtain is opened (Fig. 16). And in smart water pump we record the amount of water by using ESP11 WIFI module and we record it using a webpage.

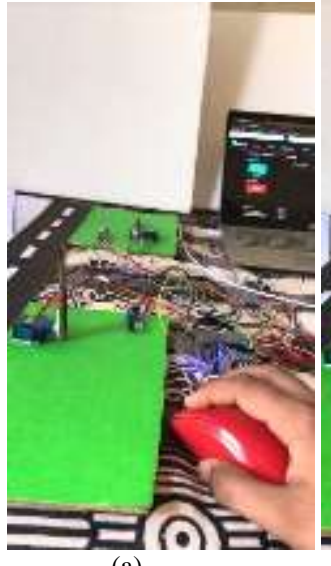

(a)

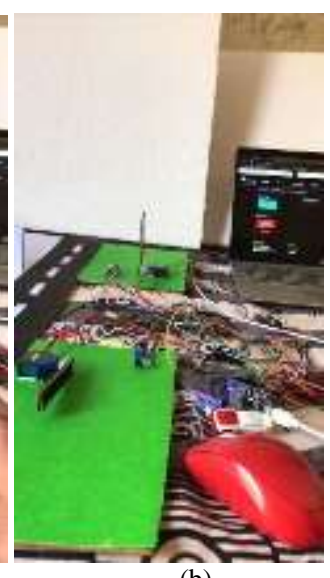

(b)
Fig. 10. Entry and Exit Doors Open through ADAFRUIT.

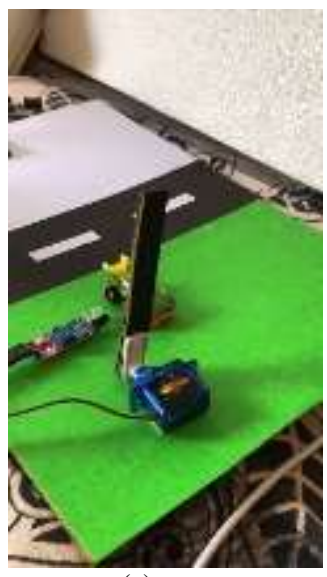

(a)

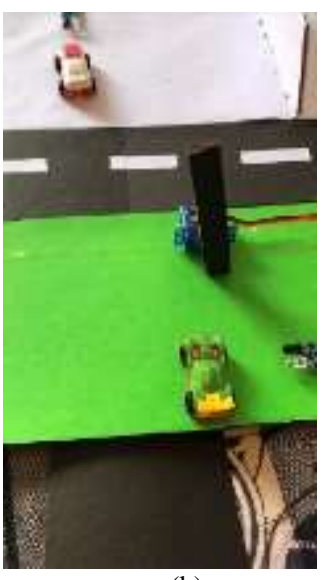

(b)
Fig. 11. Automatic Entry and Exit Doors Opening.

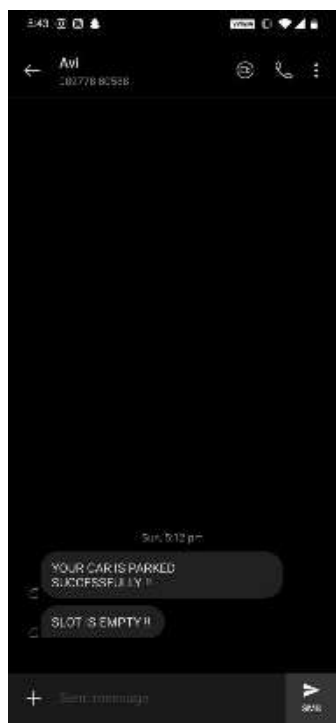

Fig. 12. SMS to Mobile for Special Parking.

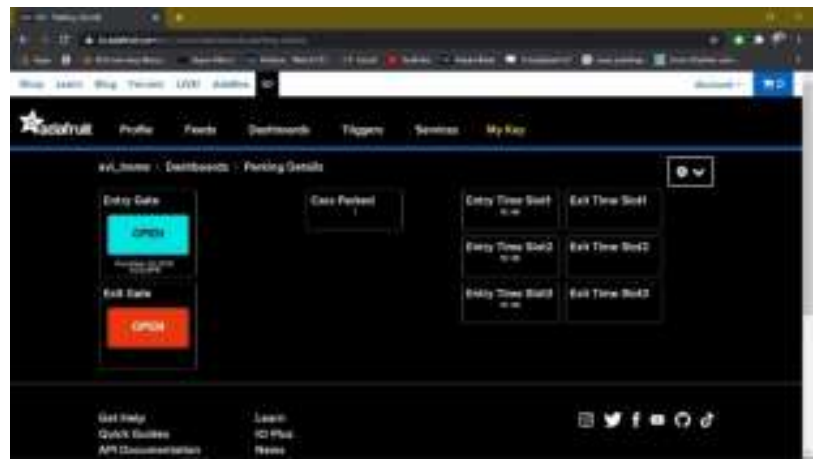

Fig. 13. Adafruit Display for Smart Parking Display.

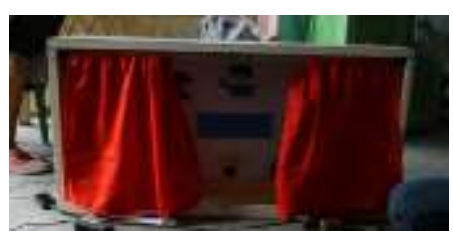

(a)

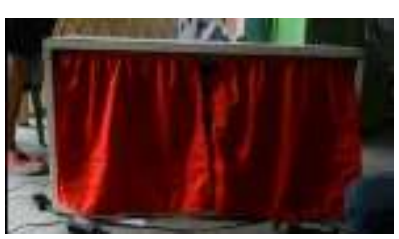

(b)
Fig. 14. Opened/Closed Window Curtain Automatically. 


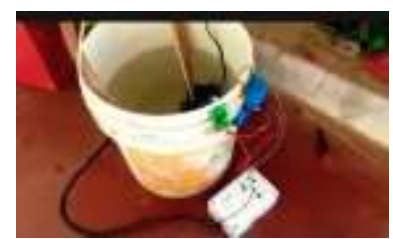

Fig. 15. Smart Water Pump.

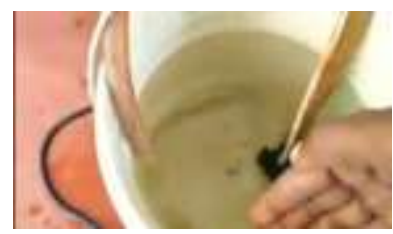

Fig. 16. Automatic Water Flow in Smart Building System.

\section{Manhole Detection System}

The output of this module is to detect the manhole. Using this process we can reduce the people falling in manhole. In this project we used GSM module and a webpage the GSM module will detect the person near the manhole using ultra sonic sensor and the person will get the message to his mobile like "manhole detected" otherwise in the webpage it will be as "Rootcleard". At first the output was displayed in LCD display they we can able to see the output in webpage also (Fig. 17). By alert message sent by the GSM will help us to avoid the accident cause by the manhole (Fig. 18).

\section{E. Smart Irrigation System using Adafruit IO}

The first output for this module is to water the plants through adafruit io setup firstly in this module we have to create the interfaces in adafruit such as temperature, light and soil moisture percentage (graph interface) and atlast we have to create an interface called motor which is used to on/off if the plant condtion is in dry then the motor should on in the setup and if the plant condtion is wet then the motor should off and hence it should show the soil moisture percentage through graph type and it should show the light condition around the plant field. Hence the theme of this project is without any human involvement it should help the farmers to water the plant field (see Fig. 19 and 20).

\section{F. Restaurant Menu Ordering System}

The main theme of this module is to print the item names and item cost and total cost of the items should print on the webserver i.e. (default IP address) firstly in this module ESP8266 is used to publish data through webserver and it is useful to print items which is given by the user and in this module Arduino uno was used and it is used to print the item names in $16 \times 2$ lcd display coming to the circuit, they are 5 push buttons which is used to display the items in $16 \times 2 \mathrm{lcd}$ as well as server IP address at last 5th pushbutton is used to print the total bill of the order which is given by the user (see Fig. 21 and 22).

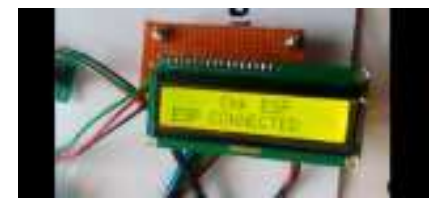

Fig. 17. LCD Display for Manhole Detection.

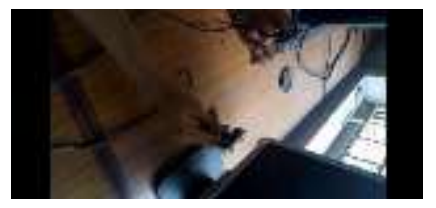

Fig. 18. Detecting the Manhole.

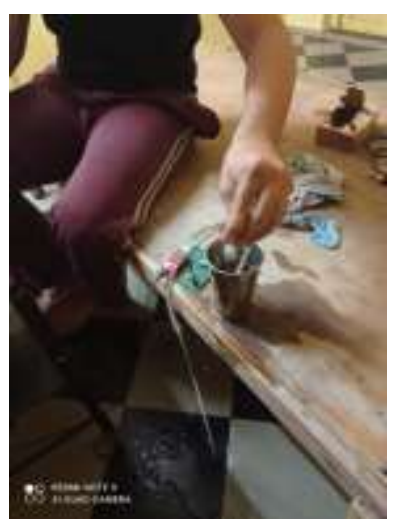

Fig. 19. Automatic Water Flow in Smart Irrigation System.

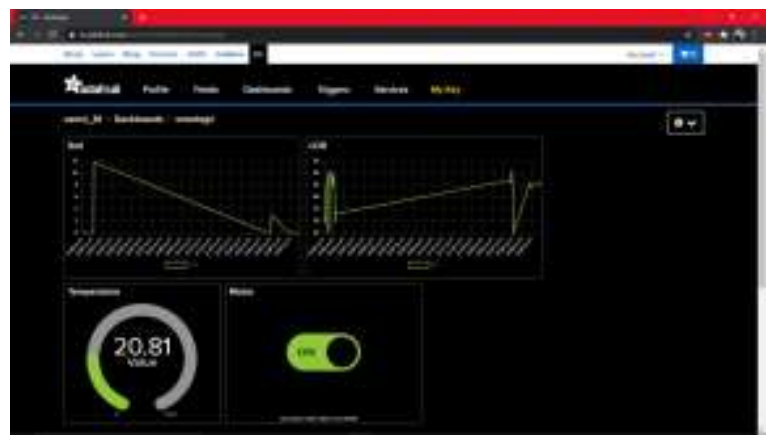

Fig. 20. ADAFRUIT Display for Smart Irrigation System.

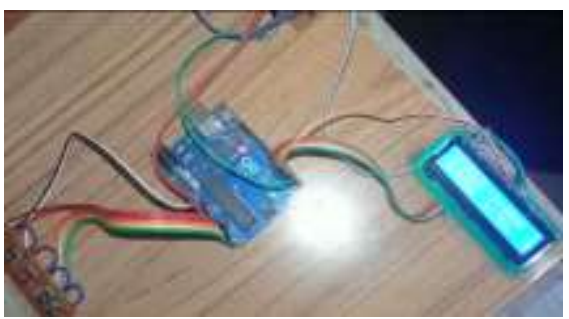

Fig. 21. LCD Display Coming to the Circuit.
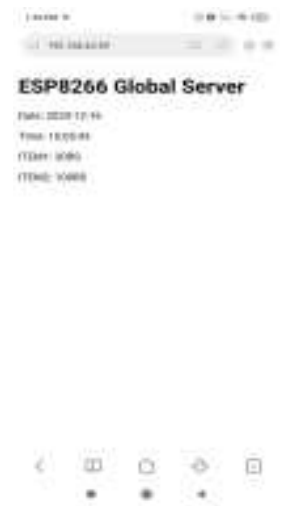

Fig. 22. Webpage Display for Restaurant Menu Ordering System. 


\section{CONCLUSION}

The main objective of this project is without any Human Involvement all the systems or elements has to work to make life easier. The required technologies in this project is Internet of Things (IoT), Embedded Systems and Networking. IoT is the most emerging Technology with so many applications like Smart Home Automation, Health Care System via Mobile, Smart Grid, Smart Farming, Smart Surveillance, etc. So, the main concept is to create a Smart City with all the advanced elements which will reduce the Human efforts and trying to Implement this one in Real Life so that there is a lot of change in society.

\section{Future SCOPE}

All these modules are designed based on the real time problems faced in the society. These can further modified to an advanced levels as following:

Smart Garbage Monitoring System: This module can be further updated as garbage separation by using the AIML Techniques merge with the Internet of Things technology. In this the dry and wet waste can be separated automatically by a machine without any human involvement this could be done though camera detection.

Smart Parking System: This module can be further updated as a ticket counter, which means in my module the human involvement is needed to distribute tokens/tickets but we can implement a ticket counter which will automatically distribute it and for this high level of surveillance is also required.

Smart Building System: This module can be further implemented as automatic motor on/off system, which means the motor which will supply the water to tank can be automatically work based on the timings given to it or based on the sensor responses.

Manhole Detection System: This module can be further implemented as tracking the location of the manholes in different areas and storing the data in the databases, so that we can able to analyze the percentages of problems placed by the people due to manholes in particular area.

Smart Irrigation System: This module can be further implemented as, storing the data in the database so that we can able to analyze the position/condition of our garden/field in every season.

Restaurant Menu Ordering System: This module can be further extended as, displaying the table number in PC whenever a person press the button on a particular table. So that we can able to track the position of the table.

\section{REFERENCES}

[1] Prof. Dr. Sandeep M. Chaware, Shriram Dighe, Akshay Joshi, Namrata Bajare, Rohini Korke, "Smart Garbage Monitoring System using Internet of Things (IOT)", IJIREEICE, vol 5, Issue1, January 2017.

[2] Husam Rajab, Tibor Cinkelr, "IoT based Smart Cities", The Institute of Electrical and Electronics Engineers, 2018.

[3] Andrea Zanella, Nicola Bui, Angelo Castellani, Lorenzo Vangelista, , and Michele Zorzi, "Internet of Things for Smart Cities", IEEE Internet of Things Journal, Vol. 1, No. 1, February 2014.

[4] Miss. Priya A. Jadhao, Miss. Sonal D. Sakhare, Miss. Kajal G. Bhaldane, Prof. Abhishek P. Narkhede, Prof. Vaibhav S. Girnale, "Smart Garbage Monitoring and Collection System using Internet of Things", A National Conference On Spectrum Of Opportunities In Science \& Engineering Technology Volume 5, Special Issue 06, April2018.

[5] Faheem, S.A. Mahmud, G.M. Khan, M. Rahman, H. Zafar, "A Survey of Intelligent Car Parking System", Vol 11, Issue 5, 2013.

[6] Anusha, Arshitha M S, Anushri, Geetanjali Bishtannavar, "Review Paper on Smart Parking System”, IJERT, Special Issue - 2019.

[7] Husam Rajab, Tibor Cinkelr,"IoT based Smart Cites", 19-21 June 2018.

[8] Nor Adni Mat Leh, Muhammad Syazwan Ariffuddin Mohd Kamaldin ,Zuraida Muhammad,"Smart Irrigation System Using Internet of Things, 7 October 2019.

[9] Hamza BENYEZZA, Mounir BOUHEDDA ,Khaoula DJELLOUT,"Smart Irrigation System Based Thingspeak and Arduino 24-25 November 2018.

[10] Kriti Taneja , Sanmeet Bhatia ,"Automatic Irrigation System using Arduino UNO,15-16 June 2017.

[11] J.Caroline EL Fiorenza , Anurag Chakraborty, R Rishi, Kaustubh Baghel ,"Smart Menu Card System",15-16 Oct 2018.

[12] Renjith V Ravi,Amrutha N R,Amritha E,Haneena.P,Jaseena.T,"An Android Based Restaurant Automation System with Touch Screen",1011 Jan 2019.

[13] Raviprakash Shriwas,Nikesh Patel, Asif Bherani,, Arti Khajone,Manish Raut,"Touchscreen Based Ordering System For Restaurants ,3-5 April 2014.

[14] XU Hongzhen,TANG Bin,SONG Wenlin,"Wireless Food Ordering System Based on Web Services ",10-11 Oct 2009.

[15] Wei, Z.; Yang, M.; Wang, L.; Ma, H.; Chen, X.; Zhong, R. Customized Mobile LiDAR System for Manhole Cover Detection and Identification. Sensors 2019.

[16] G.Gowtham, K.Hari Haran, G.Keerthee Rajan, A.Sweeto Jeison, "Sewage level maintenance using IoT" International Journal of Mechanical Engineering and Technical, vol. 9, Issue 2, February 2018.

[17] Dhanalakshmi.G, Akhil.S, Francisca Little Flower.M, Haribalambika.R, "Explosion detection and drainage monitoring system by Automation System" International Journal of Innovative research in computer and communication engineering, vol. 6, issue 2, February 2018.

[18] D.-Y., Ferranti, E. and Hadeli, H. (2013), "An intelligent building that listens to your needs", Symposium on Applied Computing, Coimbra, March 18-23. 